\title{
Maternal-Fetal Attachment and Domestic Violence in Iranian and Afghan Pregnant Women: A Cross- Cultural Study
}

\section{Mahlagha Dehghan}

Kerman University of Medical Sciences

Hakimeh Ferdosi

Kerman University of Medical Sciences

Faroukh Abazari

Kerman University of Medical Sciences

Jamileh Farokhzadian ( $\square$ farokhzadian2010@yahoo.com )

Kerman University of Medical Sciences https://orcid.org/0000-0002-9621-3486

\section{Research}

Keywords: Domestic Violence, Pregnant Mothers, Maternal-Fetal Attachment, Afghans

Posted Date: November 19th, 2020

DOl: https://doi.org/10.21203/rs.3.rs-107804/v1

License: (a) (i) This work is licensed under a Creative Commons Attribution 4.0 International License. Read Full License 


\section{Abstract}

Background: Domestic violence against pregnant women is becoming more frequent and intense. Studies have shown that women who were under more physical and psychological violence experienced a lot of stress and depression and had less ability to communicate with their fetuses. International statistics show a high prevalence of violence against Afghan women and the communities migrated to Afghanistan. Therefore, the present study aimed to compare the maternal-fetal attachment and domestic violence between Iranian and Afghan pregnant women.

Methods: This study has a descriptive-comparative cross-sectional design. The study population consisted of Iranian and Afghan pregnant women referred to Kerman Health Centers in 2018-2019. One hundred-forty-six Iranian pregnant women and 142 Afghan pregnant women were enrolled in the study by the quota sampling. Data collection tools were demographic and clinical information questionnaire, questionnaires of domestic violence against women, and maternal-fetal attachment scale.

Results: The mean score of maternal-fetal attachment in Iranian and Afghan pregnant women was higher than the average. Also, scores of maternal-fetal attachment and its dimensions in Afghan pregnant women were significantly higher than that of Iranian pregnant women $(P<0.001)$. The mean score of domestic violence was low in Iranian and Afghan pregnant women. There was no significant difference between Iranian and Afghan pregnant women in the total score of domestic violence $(P>0.05)$. There was a significant inverse correlation between maternal-fetal attachment and domestic violence in Iranian pregnant women $(P<0.05)$. In Afghan pregnant women, there was a positive and significant correlation between maternal-fetal attachment and sexual violence in while there was a significant and reverse relationship between other dimensions of attachment and violence $(P<0.05)$.

Conclusion: This study showed that the rate of violence in the studied populations was low, and maternal-fetal attachment rate is appropriate. The relationship between violence and mother-fetal attachment had a different pattern in Iranian and Afghan women. Therefore, further studies are needed to investigate the factors affecting maternal-fetal attachment, especially in Afghan women.

\section{Plain English Summary}

The literature shows a high prevalence of violence against Afghan women and the communities migrated to Afghanistan. Therefore, the present study aimed to compare the maternal-fetal attachment and domestic violence between Iranian and Afghan pregnant women. This descriptive-comparative study compared the maternal-fetal attachment and domestic violence between Iranian and Afghan pregnant women. Data were collected using questionnaire of domestic violence against women and maternal-fetal attachment scale. The mean score of maternal-fetal attachment in Iranian and Afghan pregnant women was higher than the average. Also, scores of maternal-fetal attachment and its dimensions in Afghan pregnant women were significantly higher than that of Iranian pregnant women. The mean score of domestic violence was low in Iranian and Afghan pregnant women. There was no significant difference 
between Iranian and Afghan pregnant women in the total score of domestic violence. In conclusion; the results showed that the rate of violence in the studied populations was low, and maternal-fetal attachment rate is appropriate. The relationship between violence and mother-fetal attachment had a different pattern in Iranian and Afghan women. Therefore, further studies are needed to investigate the factors affecting maternal-fetal attachment, especially in Afghan women.

\section{Introduction}

The maternal-fetal bonding begins before birth and after the first fetal movement and encourages the mother to adjust her behavior and moods to promote the safe development of the fetus. The fetus also feels and is affected by the mother's behaviors and actions [1]. Maternal-fetal attachment involves behaviors and actions that indicate maternal-fetal emotional bonding. These behaviors lead to continued parental care, proper nutrition, sleep and exercise, abstinence from alcohol and drugs, and a desire to recognize the fetus during pregnancy, which ultimately lead to the desired pregnancy outcome and improve maternal-fetal health [2]. Maternal-fetal attachment behaviors play an important role in health, acceptance of parental identity, future mother-infant relationship, child's development, and emotional stability $[3,4]$. A mental image of the fetus helps the mother conceive of the fetus as a living being within herself. According to studies, $30 \%$ of mothers in the first trimester, $63 \%$ in the second trimester, and $92 \%$ in the third trimester conceive the fetus as a real human $[1,5,6]$. Pregnant women who have a strong attachment to their fetus believe that the fetus is in contact with them and is a separate individual. These mothers think about the way the fetus moves, its similarity, and growth in later years. These emotions, which have a positive effect on attachment, help them develop a sense of protection, sensitivity, and communication with the fetus [7]. In general, the relationship between a pregnant woman and her fetus has immediate and long-term effects on maternal healthcare measures during pregnancy, neonatal and health outcomes, maternal-infant interaction, and infant attachment security [8]. Various studies have shown that age, education of wife and husband, unwanted pregnancy, economic conditions, employment status of the mother and her husband, antenatal education are factors that can have either a positive or negative impact on maternal-fetal attachment [3,9-11]. Also, desired marital relationships play an important role in increasing maternal-fetal attachment. Because mothers tend to see their fetus under the patronage of father and somehow guarantee its future. Husband's violence is one of the factors that lead to lower marital quality and maternal-fetal attachment $[11,12]$.

Another factor affecting maternal-fetal attachment is domestic violence. Violence is a pattern of behavior that is imposed through fear, intimidation, abusive behavior to apply power and control over a close individual, and includes physical, sexual, economic abuses, verbal threats, and divorce [13]. About 40$50 \%$ of women experience domestic violence in some parts of their lives. As a result, their physical and mental health is affected and sometimes leads to suicide [14]. Violence against pregnant women is a very sad event and a common phenomenon in most societies. The prevalence of domestic violence is higher than the prevalence of any pregnancy-related medical disorders such as preeclampsia, gestational diabetes, etc. [13]. Pregnancy imposes a lot of physical and psychological stress on the individual and along with other stressors such as violence can have adverse effects on the fetus, and the mother and 
these effects can increase maternal and infant mortality [14]. Studies in different countries show that domestic violence against pregnant women varies between $25-86 \%[13,15,16]$. Other studies in different countries have shown that one in three pregnant women is subjected to physical, emotional, or sexual violence by their partner [17-19]. Domestic violence has seriously negative effects on pregnant women. Domestic violence has been reported to be associated with abortion, preterm labor, low birth weight, antenatal care, early placental separation, membrane rupture, and fetal injury $[15,16,20]$. Various studies considered husbands' violence against their pregnant wife as the main cause of decreased marital quality and maternal-fetal attachment. Also, women who are subjected to physical violence cannot pay enough attention to the dimensions of the maternal-fetal attachment process because they are struggling to cope with the hostile environment in the home. As a result, the attachment rate declines in these women [21-23]. Domestic violence is not only a serious public health issue during pregnancy but also endangers the maternal-fetal health. On the other hand, regarding the impact of violence on the level of maternal-fetal attachment and the importance of maternal-fetal attachment for the health of mother and fetus in future, this study aimed to compare maternal-fetal attachment and domestic violence in Iranian and Afghan pregnant women.

\section{Materials And Methods}

\section{Study design and settings}

This study has a descriptive-comparative cross-sectional design. The study setting was health centers providing perinatal and maternal care services in Kerman city in southeastern Iran. Kerman is one of the most populous cities in terms of the number of Afghan citizens in Iran.

\section{Sampling Method And Sample Size}

Quota sampling was used in this study. The city was divided into four districts, and two health centers were randomly selected from each district. Then, convenience sampling was done between Iranian and Afghan clients to reach the appropriate sample size. According to quota sampling and sample size, equal samples were selected from each district. Inclusion criteria were Iranian and Afghan pregnant women over 15 years old. Since no similar study was found in this field, a pilot study was conducted to estimate the sample size. Fifteen Iranian pregnant women and 15 Afghan pregnant women completed the questionnaires, and then the sample size was estimated using the following formula.

$$
\mathrm{n}=\frac{\left(\mathrm{z}_{1-\frac{\alpha}{2}}+Z_{1-\beta}\right)^{2}\left(\sigma_{1}^{2}+\sigma_{2}^{2}\right)}{\left(\mu_{1}-\mu_{2}\right)^{2}}
$$


The $95 \%$ confidence interval and the test power of $1-\beta=0.9$ were considered. In the pilot study, the mean, standard deviation of domestic violence in Iranian pregnant women were $8.93 \pm 9.89$, and it was $16.53 \pm$ 21.57 in Afghan pregnant women. According to the above numbers, 127 subjects were calculated in each group, and 150 questionnaires were distributed in each group due to dropout probability. Finally, after collecting 150 questionnaires from each group and eliminating the questionnaires with more than $10 \%$ missing data, 146 questionnaires in the Iranian pregnant women group and 142 questionnaires in the Afghan pregnant women were analyzed. Therefore, the response rate of Iranian pregnant women was $97 \%$, and that of Afghan pregnant women was $94.66 \%$.

\section{Data Collection Tools}

The tools used in this study were maternal demographic and background information questionnaire, domestic violence against women questionnaire, and maternal-fetal attachment scale. The maternal demographic and background information questionnaire included 16 items about age, education, occupations of mothers and their husbands, and some other information.

\section{Domestic Violence Questionnaire}

A researcher-made questionnaire was used to assess domestic violence. An initial draft of the questionnaire was developed using the literature review and expert opinion $[13,14,22,23]$. Then, eight faculty members of Kerman School of Nursing and Midwifery assessed the questionnaire content validity. Their corrective comments were applied to the questionnaire, and the content validity index was 0.98 . The questionnaire was provided to 30 subjects ( 15 Iranian pregnant women and 15 Afghan pregnant women) for measuring reliability. Cronbach's alpha coefficient was 0.89 for Iranian pregnant women and 0.88 for Afghan pregnant women.

The questionnaire consisted of 27 items in 5 dimensions. Items 1- 6 related to verbal violence, items 712 related to physical violence, items 13-17 related to sexual violence, items 18-24 related to emotionalpsychological violence, and items 25-27 related to financial violence. The six-point Likert scale was used for scoring ( 0 = not at all, 5 = a lot). Questionnaire minimum and maximum scores were 0 and 135, respectively. A higher score showed higher domestic violence.

\section{Maternal-fetal Attachment Scale (mfas)}

Cranley first developed this self-report scale in 1981 and confirmed its reliability by alpha Cronbach's coefficient $(a=85 \%)$ [24]. Khoramroodi in Iran translated Maternal-fetal attachment scale, and its validity was confirmed with content validity, and its reliability was confirmed with test-retest $(r=0.85)$ [25]. In the present study, Cronbach's alpha coefficient was 0.78 in Iranian pregnant women and 0.81 in Afghan women. 
The questionnaire has five dimensions of interaction with the fetus (items: 1, 16, 17, 20, 24), differentiation of self (items: $4,8,18,19$ ), role taking (items: $3,5,6,9$ ), attribution of characteristics and intentions (items: $7,10,12,13,14,21$ ) and giving of self (items: $2,11,15,22,23$ ). Five-point Likert scale was used for scoring (definitely yes $=5$, yes $=4$, not sure $=3$, no $=2$, and definitely no $=1$ ). The scoring was reversed only for the phrase "I feel that my body is getting ugly." Therefore, the scale minimum and maximum scores are 24 and 120, and higher score shows higher attachment. [25].

\section{Data Collection}

The researcher referred to the selected health centers after obtaining permission from the ethics committee and the head of the School of Nursing and Midwifery. Then, she introduced herself to the clinic staff, presented a letter of introduction and explained the research, and obtained their consent and went to the primary research setting, the perinatal and maternal care unit. Before completing the questionnaire, participants were provided with necessary explanations about the objectives of the study and information confidentiality. Then, after providing a private and confidential environment, the domestic violence questionnaire and maternal-fetal attachment scale were completed by Iranian and Afghan women. Data collection lasted from 23.Oct.2018 to 19.Feb.2019. Whenever the samples needed clarification of the questions, the researcher provided sufficient explanations. Two Afghan women fluent in Persian were used for communicating with Afghan women due to difficulty in verbal communication.

\section{Statistical Analysis}

SPSS version 18 was used. The demographic and background characteristics of the samples were presented using descriptive statistics. The results of the Kolmogorov-Smirnov test showed that only the total maternal-fetal attachment score in Iranian pregnant women followed a normal distribution and other variables did not have normal distribution. Therefore, Mann-Whitney $U$ test was used to compare maternal-fetal attachment and domestic violence between Iranian and Afghan pregnant women. Spearman correlation coefficient was also used to investigate the correlation between attachment and domestic violence against pregnant women. Independent t- and ANOVA tests and Mann-Whitney, KruskalWallis and Spearman correlation coefficient tests were used to investigate maternal-fetal attachment and domestic violence variables in both groups in terms of background-demographic variables. Significance level was considered to be 0.05 .

\section{Results}

The mean ages of Iranian and Afghan pregnant women were $28.3 \pm 5.83$ and $21.84 \pm 5.92$, respectively. $66.2 \%$ of Iranian pregnant women and $97.9 \%$ of Afghan women were housewives. The majority of Iranian pregnant women were academically educated, while the majority of Afghan pregnant women were illiterate. The majority of husbands of Iranian pregnant women were academically educated, while most husbands of Afghan pregnant women had middle/high school degrees (Table 1). The majority of 
pregnant women in both groups had done ultrasonography for their current pregnancy. The gender of the fetus was female in the majority of Iranian samples, and it was male in the majority of the afghan samples. The majority of samples had healthy embryos. The majority of samples in both groups had no history of abortion and infertility. The majority of Iranian samples had wanted pregnancy, but the majority of Afghan samples had unwanted pregnancy. The majority of the samples and their husbands in both groups had no history of physical and mental illness (Table 1). 
Table 1

Background and demographic characteristics of pregnant women

\begin{tabular}{|c|c|c|c|c|}
\hline \multirow[t]{2}{*}{ Variable } & \multicolumn{2}{|c|}{$\begin{array}{l}\text { Iranian pregnant women } \\
\text { (146) }\end{array}$} & \multicolumn{2}{|c|}{$\begin{array}{l}\text { Afghan pregnant women } \\
(142)\end{array}$} \\
\hline & Mean & SD & Mean & SD \\
\hline Age (yr.) & 28.3 & 5.83 & 21.84 & 5.92 \\
\hline Age at the time of marriage (yr.) & 23.43 & 5.1 & 17.18 & 2.45 \\
\hline Husband's age (yr.) & 31.58 & 6.04 & 24.86 & 6.68 \\
\hline $\begin{array}{l}\text { Husband's age at the time of marriage } \\
\text { (yr.) }\end{array}$ & 26.8 & 4.78 & 19.82 & 3.34 \\
\hline \multirow[t]{2}{*}{ Marital duration (yr.) } & 5.28 & 4.39 & 4.9 & 4.87 \\
\hline & Frequency* & Percentage & Frequency* & Percentage \\
\hline \multicolumn{5}{|l|}{ Occupation } \\
\hline Unemployed & 96 & 66.2 & 139 & 97.9 \\
\hline Employed & 49 & 33.8 & 3 & 2.1 \\
\hline \multicolumn{5}{|l|}{ Education level } \\
\hline Uneducated & 4 & 2.8 & 115 & 81 \\
\hline Middle/high school & 12 & 8.2 & 25 & 17.6 \\
\hline Diploma & 47 & 32.2 & 2 & 1.4 \\
\hline Academic & 83 & 56.8 & - & - \\
\hline \multicolumn{5}{|l|}{ History of addiction } \\
\hline Yes & 1 & 0.7 & 0 & 0 \\
\hline No & 145 & 99.3 & 142 & 100 \\
\hline \multicolumn{5}{|l|}{ Marriage numbers } \\
\hline Once & 141 & 96.6 & 139 & 97.9 \\
\hline More than once & 5 & 3.4 & 3 & 2.1 \\
\hline \multicolumn{5}{|l|}{ Husband nationality } \\
\hline Iranian & 142 & 97.2 & 2 & 1.4 \\
\hline Afghan & 3 & 2.1 & 140 & 98.6 \\
\hline Others & 1 & 0.7 & - & - \\
\hline Husband's job & & & & \\
\hline
\end{tabular}




\begin{tabular}{|c|c|c|c|c|}
\hline \multirow[t]{2}{*}{ Variable } & \multicolumn{2}{|c|}{$\begin{array}{l}\text { Iranian pregnant women } \\
\text { (146) }\end{array}$} & \multicolumn{2}{|c|}{$\begin{array}{l}\text { Afghan pregnant women } \\
\text { (142) }\end{array}$} \\
\hline & Mean & SD & Mean & SD \\
\hline Unemployed & 6 & 4.1 & 16 & 11.3 \\
\hline Self-employed & 81 & 55.5 & 122 & 85.9 \\
\hline Employed & 59 & 40.4 & - & - \\
\hline Worker & - & - & 4 & 2.8 \\
\hline \multicolumn{5}{|l|}{ Husband's education } \\
\hline Uneducated & 5 & 3.4 & 57 & 40.1 \\
\hline Middle/high school & 9 & 6.2 & 74 & 52.1 \\
\hline Diploma & 52 & 35.6 & 8 & 5.7 \\
\hline Academic & 80 & 54.8 & 3 & 2.1 \\
\hline \multicolumn{5}{|c|}{ Monthly income (Tomans) } \\
\hline$<1500000$ & 46 & 32.2 & 88 & 62.9 \\
\hline $1500000-2500000$ & 58 & 40.6 & 45 & 32.1 \\
\hline$>2500000$ & 39 & 27.2 & 7 & 5 \\
\hline \multicolumn{5}{|l|}{ Husband's addiction } \\
\hline Yes & 4 & 2.7 & 3 & 2.1 \\
\hline No & 142 & 97.3 & 139 & 97.9 \\
\hline \multicolumn{5}{|c|}{ Husband's marriage No. } \\
\hline Once & 138 & 95.2 & 131 & 92.3 \\
\hline More than once & 7 & 4.8 & 11 & 7.7 \\
\hline \multicolumn{5}{|l|}{ Housing status } \\
\hline Personal & 61 & 42.4 & 10 & 7.1 \\
\hline Leased & 72 & 50 & 115 & 82.1 \\
\hline Others & 11 & 7.6 & 15 & 10.8 \\
\hline \multicolumn{5}{|c|}{$\begin{array}{l}\text { Ultrasonography in the current } \\
\text { pregnancy }\end{array}$} \\
\hline Yes & 131 & 90.3 & 87 & 61.7 \\
\hline No & 14 & 9.7 & 54 & 38.3 \\
\hline
\end{tabular}




\begin{tabular}{|c|c|c|c|c|}
\hline \multirow[t]{2}{*}{ Variable } & \multicolumn{2}{|c|}{$\begin{array}{l}\text { Iranian pregnant women } \\
\text { (146) }\end{array}$} & \multicolumn{2}{|c|}{$\begin{array}{l}\text { Afghan pregnant women } \\
\text { (142) }\end{array}$} \\
\hline & Mean & SD & Mean & SD \\
\hline \multicolumn{5}{|l|}{ Fetus gender } \\
\hline Male & 39 & 26.9 & 74 & 52.9 \\
\hline Female & 58 & 40 & 34 & 24.2 \\
\hline Unknown & 48 & 33.1 & 32 & 22.9 \\
\hline \multicolumn{5}{|c|}{ Fetal abnormality } \\
\hline Yes & 6 & 4.2 & 3 & 2.1 \\
\hline No & 136 & 95.8 & 139 & 97.9 \\
\hline \multicolumn{5}{|l|}{ Abortion history } \\
\hline Yes & 39 & 26.9 & 34 & 23.9 \\
\hline No & 106 & 73.1 & 108 & 76.1 \\
\hline \multicolumn{5}{|l|}{ Infertility history } \\
\hline Yes & 6 & 4.2 & 3 & 2.1 \\
\hline No & 137 & 95.8 & 137 & 97.9 \\
\hline \multicolumn{5}{|c|}{ Wanted pregnancy } \\
\hline Yes & 105 & 72.4 & 61 & 43 \\
\hline No & 40 & 27.6 & 81 & 57 \\
\hline \multicolumn{5}{|l|}{ Children No. } \\
\hline One & 50 & 34.2 & 31 & 21.8 \\
\hline Two & 26 & 17.8 & 18 & 12.7 \\
\hline More than two & 6 & 4.2 & 36 & 25.4 \\
\hline Unanswered & 64 & 43.8 & 57 & 40.1 \\
\hline \multicolumn{5}{|c|}{ History of physical illness } \\
\hline Yes & 7 & 4.9 & 6 & 4.3 \\
\hline No & 137 & 95.1 & 135 & 95.7 \\
\hline \multicolumn{5}{|c|}{ History of mental illness } \\
\hline Yes & 0 & 0 & 3 & 2.1 \\
\hline
\end{tabular}




\begin{tabular}{|c|c|c|c|c|}
\hline \multirow[t]{2}{*}{ Variable } & \multicolumn{2}{|c|}{$\begin{array}{l}\text { Iranian pregnant women } \\
\text { (146) }\end{array}$} & \multicolumn{2}{|c|}{$\begin{array}{l}\text { Afghan pregnant women } \\
\text { (142) }\end{array}$} \\
\hline & Mean & SD & Mean & SD \\
\hline No & 145 & 100 & 139 & 97.9 \\
\hline \multicolumn{5}{|c|}{ Husband's physical illness } \\
\hline Yes & 7 & 14.8 & 2 & 1.4 \\
\hline No & 138 & 95.2 & 139 & 98.6 \\
\hline \multicolumn{5}{|c|}{ Husband's mental illness } \\
\hline Yes & 1 & 0.7 & 2 & 1.4 \\
\hline No & 144 & 99.3 & 139 & 98.6 \\
\hline
\end{tabular}

The mean scores of maternal-fetal attachment in Iranian and Afghan pregnant women were $92.87 \pm$ 12.55 and $103.6 \pm 19.65$, respectively. According to the median score of the questionnaire, which is 72 , the maternal-fetal attachment rate was higher than the average in both groups. Also, the total scores of mother-fetal attachment and all its dimensions in Afghan pregnant women were higher than that in Iranian pregnant women (Table 2).

Table 2

Comparison of scores of maternal-fetal attachment and its dimensions between Iranian and Afghan pregnant women

\begin{tabular}{|lllllll|}
\hline $\begin{array}{l}\text { Group } \\
\text { Maternal-fetal attachment }\end{array}$ & \multicolumn{2}{l}{$\begin{array}{l}\text { Iranian pregnant } \\
\text { women }\end{array}$} & $\begin{array}{l}\text { Afghan pregnant } \\
\text { women }\end{array}$ & $\begin{array}{l}\text { Mann- } \\
\text { Whitney U } \\
\text { test }\end{array}$ & $\begin{array}{l}\text { P- } \\
\text { value }\end{array}$ \\
\cline { 2 - 5 } & Mean & SD & Mean & SD & \\
\hline Interaction with the fetus & 17.51 & 3.84 & 21.89 & 5.27 & -8.2 & $<$ \\
\hline Differentiation of self & 17.04 & 2.85 & 17.73 & 4.0 & -4.82 & $<$ \\
\hline Role taking & 17.06 & 2.35 & 18.06 & 3.27 & -5.52 & $<$ \\
\hline $\begin{array}{l}\text { Attribution of specific } \\
\text { characteristics and intentions }\end{array}$ & 21.18 & 4.18 & 25.19 & 6.37 & -6.98 & $<$ \\
\hline Giving of self & & & & & & 0.001 \\
\hline Total & 20.08 & 2.9 & 20.7 & 3.13 & -2.29 & 0.001 \\
\hline
\end{tabular}


Among the underlying variables of Iranian pregnant women, the total maternal-fetal attachment score was significantly different only in husband nationality. In other words, pregnant women with non-Iranian husbands had higher maternal-fetal attachment score than those with Iranian husbands $(P<0.05)$. The older the age of Afghan pregnant women, and their husbands, as well as the higher their marital duration, the lower the maternal-fetal attachment score, and the severity of these relationships, was moderate $(r=$ 0.2-0.4) $(P<0.05)$. Also, the maternal-fetal attachment score was higher in Afghan women with unwanted pregnancy than those with wanted pregnancy $(P<0.05)$.

The mean scores of domestic violence in Iranian pregnant women and Afghan pregnant women were $9.63 \pm 8.13$ and $10.51 \pm 9.1$, respectively. As the median score of the questionnaire was 67.5 , the level of domestic violence was low in both groups. Also, there was no significant difference between Iranian and Afghan pregnant women in the total score of domestic violence. However, among the dimensions of domestic violence, the mean dimension of verbal and emotional-psychological violence in Iranian pregnant women was significantly higher than that of Afghan pregnant women, while the mean dimension of sexual violence in Afghan pregnant women was significantly higher than that of Iranian pregnant women. There were also no differences between the two groups in physical and financial violence (Table 3).

Table 3

Comparison of Domestic Violence Score and its Dimensions between Iranian and Afghan Pregnant Women

\begin{tabular}{|lllllll|}
\hline $\begin{array}{l}\text { Group } \\
\text { Domestic violence }\end{array}$ & \multicolumn{2}{l}{$\begin{array}{l}\text { Iranian pregnant } \\
\text { women }\end{array}$} & $\begin{array}{l}\text { Afghan pregnant } \\
\text { women }\end{array}$ & $\begin{array}{l}\text { Mann-Whitney U } \\
\text { test }\end{array}$ & $\begin{array}{l}\text { P- } \\
\text { value }\end{array}$ \\
\cline { 2 - 5 } & Mean & SD & Mean & SD & \\
\hline Verbal & 2.62 & 3.32 & 1.12 & 3.04 & -7.14 & $<$ \\
\hline Physical & 0.32 & 1.76 & 0.59 & 2.27 & -1.58 & 0.001 \\
\hline Sexual & 4.28 & 2.3 & 6.98 & 4.37 & -5.44 & 0.11 \\
\hline $\begin{array}{l}\text { Emotional- } \\
\text { psychological }\end{array}$ & 2.21 & 3.24 & 1.34 & 3.41 & -4.76 & 0.001 \\
\hline Financial & 0.21 & 0.66 & 0.48 & 1.25 & -1.45 & 0.001 \\
\hline Total & 9.63 & 8.13 & 10.51 & 9.1 & -0.44 & 0.15 \\
\hline
\end{tabular}

There was no significant association between background variables and total score of domestic violence in Iranian pregnant women $(P>0.05)$. The higher the age of afghan pregnant women, their husbands, and marital duration, the higher the score of domestic violence and the severity of these relationships was moderate $(r=0.2-0.4)(P<0.05)$. Pregnant women with a personal house also reported more violence than other Afghan women. Women whose fetal gender was unknown reported more violence. Women who had unwanted pregnancies reported higher rates of violence than women who had wanted 
pregnancy. Women with more than two children reported more violence than other Afghan pregnant women. Afghan pregnant women with physical illness reported more violence than healthy women $(\mathrm{P}<$ 0.05).

There was a significant inverse relationship between the mean maternal-fetal attachment and the mean domestic violence in Iranian pregnant women. In other words, the higher the score of domestic violence, the lower the maternal-fetal attachment score, and vice versa. Also, the maternal-fetal attachment score had a poor and inverse relationship only with the dimensions of verbal, emotional-psychological, and financial violence (Table 4).

Table 4

Correlation between maternal-fetal attachment and domestic violence in Iranian pregnant women

\begin{tabular}{|c|c|c|c|c|c|c|c|}
\hline \multirow[t]{2}{*}{ Variable } & & \multicolumn{6}{|c|}{ Domestic violence in Iranian pregnant women } \\
\hline & & Verbal & Physical & Sexual & $\begin{array}{l}\text { Emotional- } \\
\text { psychological }\end{array}$ & Financial & Total \\
\hline \multirow{6}{*}{$\begin{array}{l}\text { Maternal- } \\
\text { fetal } \\
\text { attachment }\end{array}$} & $\begin{array}{l}\text { Interaction with } \\
\text { the fetus }\end{array}$ & -0.14 & 0.01 & -0.15 & -0.16 & -0.14 & $\overline{0.19 *}$ \\
\hline & $\begin{array}{l}\text { Differentiation } \\
\text { of self }\end{array}$ & -0.14 & 0.01 & -0.01 & -0.08 & -0.08 & $\overline{0.07}$ \\
\hline & Role taking & -0.16 & 0.01 & 0.05 & $-0.17^{\star}$ & $-0.17^{\star}$ & $\overline{0} .12$ \\
\hline & $\begin{array}{l}\text { Attribution of } \\
\text { specific } \\
\text { characteristics } \\
\text { and intentions }\end{array}$ & -0.12 & 0.01 & -0.08 & -0.09 & $-0.18^{*}$ & $\overline{0} .12$ \\
\hline & Giving of self & $\overline{0} .22^{\star \star}$ & $-0.19 *$ & 0.06 & -0.11 & $-0.22 \star \star$ & $\overline{0} .12$ \\
\hline & Total & $\overline{0} .20 *$ & -0.03 & -0.07 & $-0.17^{\star}$ & $-0.22^{*}$ & $\overline{0.18 *}$ \\
\hline
\end{tabular}

There was no significant association between the mean total score of maternal-fetal attachment and the mean total score of domestic violence in Afghan pregnant women. However, there was a significant inverse association amongst verbal, physical, emotional-psychological and financial violence and score of maternal-fetal attachment and all its dimensions. In other words, the higher the scores of these dimensions, the lower the scores of maternal-fetal attachment and its dimensions, and vice versa. Also, there was a direct and moderate association between the dimension of sexual violence and the scores of maternal-fetal attachment and all its dimensions. In other words, the higher the sexual violence, the higher the maternal-fetal attachment rate in Afghan pregnant women (Table 5). 
Table 5

Correlation between maternal-fetal attachment and domestic violence in Afghan pregnant women

\begin{tabular}{|c|c|c|c|c|c|c|c|}
\hline \multirow[t]{2}{*}{ Variable } & & \multicolumn{6}{|c|}{ Domestic violence in Afghan pregnant women } \\
\hline & & Verbal & Physical & Sexual & $\begin{array}{l}\text { Emotional- } \\
\text { psychological }\end{array}$ & Financial & Total \\
\hline \multirow{6}{*}{$\begin{array}{l}\text { Maternal- } \\
\text { fetal } \\
\text { attachment }\end{array}$} & $\begin{array}{l}\text { Interaction with } \\
\text { the fetus }\end{array}$ & $\overline{0} .64 * *$ & $-0.26^{\star \star}$ & $0.27 * \star$ & $-0.51^{\star *}$ & $-0.43^{\star \star}$ & $\overline{0.2 *}$ \\
\hline & $\begin{array}{l}\text { Differentiation } \\
\text { of self }\end{array}$ & $\overline{0.53 * \star}$ & $-0.18^{\star}$ & $0.28 * \star$ & $-0.45^{\star \star}$ & $-0.39 * *$ & $\overline{0} .12$ \\
\hline & Role taking & $\overline{0} .58^{\star \star}$ & $-0.21^{\star}$ & $0.3^{\star \star}$ & $-0.46^{\star \star}$ & $-0.37^{\star \star}$ & $\overline{0} .13$ \\
\hline & $\begin{array}{l}\text { Attribution of } \\
\text { specific } \\
\text { characteristics } \\
\text { and intentions }\end{array}$ & $\overline{0.56 * *}$ & $-0.21 *$ & $0.26 * \star$ & $-0.38^{\star \star}$ & $-0.32^{* *}$ & $\overline{0} .14$ \\
\hline & Giving of self & $\overline{0.44 * \star}$ & $-0.13^{*}$ & $0.35^{\star \star}$ & $-0.38^{\star *}$ & $-0.33^{\star \star}$ & $\overline{0} .01$ \\
\hline & Total & $\overline{0.54^{\star \star}}$ & $-0.2^{\star}$ & $0.34^{\star *}$ & $-0.36^{\star \star}$ & $-0.3^{\star *}$ & $\overline{0} .04$ \\
\hline
\end{tabular}

\section{Discussion}

The results of this study showed that maternal-fetal attachment in pregnant Iranian and Afghan pregnant women was more than average. Also, maternal-fetal attachment and all its dimensions were significantly higher in Afghan pregnant women than in Iranian pregnant women. Results of several studies on Iranian pregnant women showed that maternal-fetal attachment in pregnant women was more than average [1$3,26]$. Also, the results of various studies on pregnant women in Korea, Africa, Turkey, and the USA showed that the maternal-fetal attachment was also above average, all of which were in line with the present study $[4,7,8,27]$. But O'Malley et al. (2018) in Ireland showed that the rate of maternal-fetal attachment in Irish pregnant women was moderate [28]. This inconsistency may be due to the low sample size, differences in research methodology, and cultural differences. Based on the above studies, it can be concluded that maternal-fetal attachment rate among pregnant women (either in Iran or in different countries) is favorable. Maternal attachment to the fetus during pregnancy affects the formation and development of a safe and healthy child attachment [9]. With increased maternal attachment to the fetus, mothers are more likely to engage in health behaviors during pregnancy such as stopping smoking and alcohol, proper nutrition, exercise, continued antenatal care, tendency to recognize the fetus, and attending birth preparation classes, as well as increasing breastfeeding rates. All of these behaviors lead to a satisfactory pregnancy outcome and improve maternal-fetal health [10]. Therefore, it is necessary to consider various factors that may affect maternal-fetal attachment when caring for 
pregnant women. For example, in the present study, pregnant women with non-Iranian spouses had higher maternal-fetal attachment scores than those with Iranian spouses, and Afghan women's age, spouse age, marital length, and unwanted pregnancy influenced maternal-fetal attachment rate. In other words, the higher the age of pregnant women, their spouses and duration of marriage, the lower the maternal-fetal attachment score and the severity of these relationships was moderate. Also, the maternalfetal attachment score of Afghan women with unwanted pregnancy was higher than that of Afghan pregnant women with wanted pregnancy. In the studies, older age [1, 3, 28], low gestational age [3, 10], low education $[3,10,28]$, low education-related jobs such as agriculture $[1,3,10]$, dissatisfaction with fetus gender [3], complications of current pregnancy [3], and unwanted pregnancy [10] reduce maternalfetal attachment and antenatal education [4], number of pregnancies [1,3, 10], and breastfeeding experience [4] increases the maternal-fetal attachment. These studies were inconsistent with the present study. But among the above variables, age was in line with Afghan women. No study was found to investigate maternal-fetal attachment in Afghan women.

The results of this study showed that the level of domestic violence was low in Iranian and Afghan pregnant women. Besides, verbal and emotional-psychological abuses in Iranian pregnant women were significantly higher than that of Afghan pregnant women, while sexual abuse in Afghan pregnant women was significantly higher than that in Iranian pregnant women. There was also no difference between the two groups in physical abuse, financial abuse, and total score of domestic violence. The Cengiz et al. (2013) study in Turkey, the Boru Bifftu et al. (2017) study in northwest Ethiopia, as well as the results of two studies in 2016 and 2019 in Nepal were consistent with the present study and showed that the level of domestic violence against pregnant women was low in these regions $[15,16,20,29]$. But the Yohannes et al. (2019) study in southeastern Ethiopia and the Fekadu et al. (2018) study in northwest Ethiopia found that the rate of domestic violence against pregnant women was high in these regions $[17,30]$. These studies were inconsistent with the present study. Differences in sample size, cultural differences in different countries and communities, differences in education level, inaccessibility to accurate information about marital relationship, and differences in data collection questionnaires can lead to inconsistencies amongst studies. Studies conducted on Iranian pregnant women showed that domestic violence was high in these women $[13,14,31]$. These studies were also inconsistent with the present study. Reasons for such inconsistency can be differences in sample size, research method, differences in questionnaires used to measure the domestic violence rate, and cultural differences in respondents' willingness to disclose their marital experiences. In this study, despite the trust-building, it should be noted that since domestic violence is related to the privacy of one's life, the women under investigation might either have denied the violence or have not stated it correctly for some reasons. The results of the studies showed that the most common type of violence was sexual one and then psychological and emotional violence $[14,17,20,29]$ which were in line with the present study. But Yohannes et al.'s (2019) study in southeastern Ethiopia was not consistent with the present study which showed that physical violence had the highest rate of violence among pregnant women [30]. Also, the results of Hassan et al. (2013) study showed that physical violence and psychological violence were the most common types of violence in this study. This study was inconsistent with the present study regarding physical violence [13]. 
Kamali et al. (2015) study found that the most common type of violence was related to the physical, psychological, and sexual violence, respectively. This study investigated violence in urban and rural pregnant women. Violence was high in both communities, but physical, psychological, and sexual violence on rural pregnant women was higher than that on urban pregnant women [30]. Domestic violence during pregnancy increases the risk of miscarriage, vaginal bleeding, cesarean section, low birth weight and delayed growth in the uterus [13-15]. Therefore, it is necessary to take into account various factors that may affect domestic violence when taking care of pregnant women. For example, in the present study, variables such as age, spouse's age, marital duration, housing status, fetus gender, wanted pregnancy, number of children, and history of physical illness in the afghan women influenced the rate of domestic violence. In other words, the higher the age of pregnant women, their spouses and the duration of marriage, the higher the score of domestic violence. Pregnant women with a personal house, women whose fetus gender was unknown, unwanted pregnancy, women with more than two children, and women with physical illness reported more violence than other Afghan women. In other studies, age [14, $31]$, spouse's age [31], education [13, 16, 31], economic status [13, 31], spouse's addiction (smoking and alcohol) $[13,14,30,31]$, number of pregnancies and children $[13,31]$, duration of marriage [14, 31], experience of previous marriage [14], unwanted pregnancy [16] and spouse's occupation [13, 30] influenced the rate of violence against pregnant women. These studies were inconsistent with the population of Iranian pregnant women but consistent with Afghan pregnant women in terms of age, spouse's age, number of children, duration of marriage, and unwanted pregnancy. It should be noted that no study has examined the rate of domestic violence against pregnant Afghan women. Also, in searches of databases, we were unable to find a valid and up-to-date study on violence against Afghan women. The only case was the statistics published by European Union in 2017 showing that the violence against Afghan women was high. Of the 3778 registered cases of violence per year, 231 cases were homicides, 1003 were assaults, and 38 were rapes [32]. In Afghan society, women's decision-making has been limited, and their vulnerability to violence increased due to the wrong cultural traditions such as early marriage, exchange marriage, and marriage with conditional bride pricing. Also according to the culture dominating the country, domestic violence must be resolved in the family and remained a private matter in the family environment. Partner's violence is not disclosed due to fear of losing family honor. $89 \%$ of Afghan women express satisfaction with their husbands in the health centers while being violated. Also, $50 \%$ of women believe that their husbands have the right to beat them in the case of disobedience [33].

The results of this study showed that the higher the domestic violence and the dimensions of verbal, emotional-psychological, and financial abuses in Iranian pregnant women, the lower the maternal-fetal attachment. The higher the verbal, physical, emotional-psychological, and financial abuses in pregnant Afghan women, the lower the maternal-fetal attachment, while the higher the sexual abuse, the higher the maternal-fetal attachment and all its dimensions. The results of the studies by Almeida et al. (2013) in Portugal and Ghaffari et al. (2018) in Iran showed that the higher the domestic violence and physical abuse, the lower the maternal-fetal attachment in pregnant women [21, 23]. This study was not consistent with Iranian pregnant women, but it was consistent with Afghan women. Differences in research method, cultural differences, socioeconomic characteristics and method of data collection, different individual 
and social characteristics in two populations in two different cities, low number of samples under study and impact of mental states of samples on responses can cause such differences in the results of studies. Ghodrati et al. (2017) in their study concluded that there was a significant relationship between maternal-fetal attachment and social violence, but there was no relationship between maternal-fetal attachment and psychological, physical, financial, and sexual violence [22]. This study was inconsistent with the present study. The reasons for inconsistency include differences in sample size, cultural differences between individuals in two different cities, differences in data collection questionnaires, and selection of 24- to 35-week gestational age for samples. From the above studies, it can be concluded that violence against pregnant women reduces maternal-fetal attachment. Women who are victims of domestic violence have a negative attitude toward pregnancy and their fetus. It is recommended to reduce and control violence, conduct family and marital counseling to increase maternal attachment to the fetus and improve motherhood process in these women [21,23]. The results of this study showed that the higher the sexual violence, the higher the maternal attachment to fetus in afghan pregnant women. To justify this result, one might point to a systematic study conducted by Vogel in 2013 , in which $75 \%$ of women believed that sex, whether with consent or not, was a woman's duty [33]. However, further research is needed on the Afghan pregnant women population and the cultures dominating this community to justify the results of this study properly.

\section{Limitations}

Among the limitations of this study were "over-reporting" and "under-reporting" by volunteers. "Underreporting" is more common than "over-reporting" in socially unacceptable phenomena such as violence. Another limitation of the study was the inclusion of all pregnant mothers regardless of gestational age, which may affect the results of the study.

\section{Conclusion}

In general, this study showed that the level of violence in the studied populations was low, and the maternal-fetal attachment rate was appropriate. However, violence had a negative role in maternal-fetal interaction in Iranian pregnant women, while there was a more complicated relationship between different dimensions of violence and maternal-fetal attachment in Afghan women, and there was a positive relationship in some dimensions while there was a negative relationship in some other dimensions. Therefore, further studies are needed to investigate the factors affecting maternal-fetal attachment, especially in Afghan women.

\section{Abbreviations}

MFAS

Maternal-fetal attachment scale

\section{Declarations}




\section{Acknowledgements}

The researchers appreciate all pregnant women who gave their time so generously in order to participate in the study.

\section{Authors' contributions}

$\mathrm{MD}, \mathrm{HF}, \mathrm{FA}$, and JF contributed to conceiving and designing the research. The data were collected, analyzed, and interpreted by MD, HF, FA, and JF. MD, HF, and JF contributed equally in writing the manuscript and approved thefinal manuscript.

\section{Funding}

This research received no specific grant from any funding agency in the public, commercial, or not-forprofit sectors.

\section{Availability of data and materials}

The datasets generated and analyzed during the current study are available from the corresponding author on reasonable request.

\section{Ethics approval and consent to participate}

Ethics Committee of Kerman University of Medical Sciences approved the protocol (IR.KMU.REC.1397.243). Samples entered and withdrew the study with personal consent. Ethics were observed, including respect for the rights and confidentiality of the participants' secrets. The study imposed no cost on the patients and participants' no willingness to involve in the study did not affect the process of care for the pregnant women.

\section{Consent for publication}

Not applicable.

\section{Competing interests}

The authors declare that they have no competing interests.

\section{References}

1. Ekrami F, Mirghafourvand M, Charandabi S, Kheyradin J: Maternal-fetal attachment and its sociodemographic determinants in women with unplanned pregnancy. Int $J$ Women's Heal Reprod Sci [Internet] 2019, 7(1):106-111.

2. Maddahi M, Dolatian $M$, Khoramabadi $M$, Talebi A: Correlation of maternal-fetal attachment and health practices during pregnancy with neonatal outcomes. Electron physician 2016, 8(7):2639-2644. 
3. Jamshidimanesh M, Astaraki L, Behboodi M, Taghizadeh Z, Haghani H: Maternal-Fetal Attachment and its Associated Factors Mansoureh. J Fac Nurs Midwifery, Tehran Univ Med Sci 2012, 18(5).

4. Yu M, Kim M: The Contribution of Maternal-Fetal Attachment: Taegyo, Maternal Fatigue and Social Support during Pregnancy. Child Heal Nurs Res 2014, 20(4):247.

5. Brandon A, Pitts S, Denton W, Stringer C, Evans H: a History of the Theory of Prenatal Attachment. J Prenat Perinat Psychol Heal [Internet] 2009, 23(4):201-222.

6. Ossa X, Bustos L, Fernandez L: Prenatal attachment and associated factors during the third trimester of pregnancy in Temuco, Chile. Midwifery [Internet]2012, 28(5):689-696.

7. Güney E, Uçar T: Effect of the fetal movement count on maternal-fetal attachment. Japan J Nurs Sci 2019, 16(1):71-79.

8. Hopkins J, Miller J, Butler K, Gibson L, Hedrick L, Boyle D: The relation between social support, anxiety and distress symptoms and maternal fetal attachment. J Reprod Infant Psychol [Internet] 2018, 36(4):381-392.

9. Hosseinian S, Monavvar Yazdi S, Alavinezhad S: The Effectiveness of Fetal Attachment Training Program on Maternal- Fetal Relationship and Mental Health of Pregnant Women. Q J Child Ment Heal 2016, 2(4):75-88.

10. Torshizi M: The Different Dimensions of Maternal Attachment Behaviors and Some Related Factors in Pregnant Women Referred to Birjand Health Centers in 2012. Iran J Midwifery Infertil 2013, 16(72):13-21.

11. Torshizi M, Sharifzadeh G: Maternal -fetal attachment and associated factors in pregnant women referred to Birjand health centers (2012). Birjand Univ Med Sci 2013, 20(3).

12. sadeghi sahebzad E, Baghdari N, Kheirkhah M: The relationship between marital satisfaction and social support with maternal attachment to fetus in pregnant women with history of fetal or neonatal death. Iran J Midwifery Infertil 2014, 17(106):16-22.

13. Hassan M, Kashanian M, Hassan M, Roohi M, Yousef H: Domestic violence: prevalence during pregnancy and associated maternal outcomes. J Urmia Univ Med Sci 2014, 24(11):1009-1010.

14. Nejatizade A, Roozbeh N, Pormehr Yabandeh A, Dabiri F, Kamjoo A, Shahi A: Prevalence of domestic violence on pregnant women and maternal and neonatal outcomes in Bandar Abbas, Iran. Electron physician [Internet] 2017, 9(9):1-17.

15. Cengiz H, Kanawati A, Yildiz Ş, Süzen S, Tombul T: Domestic violence against pregnant women: A prospective study in a metropolitan city, İstanbu. J Turkish Ger Gynecol Assoc 2014, 15(2):74-77.

16. Bifftu B, Dachew B, Tadesse Tiruneh B, Zewoldie A: Domestic Violence among Pregnant Mothers in Northwest Ethiopia: Prevalence and Associated Factors. Adv Public Heal 2017, 2017:1-6.

17. Fekadu E, Yigzaw G, Gelaye K, Ayele T, Minwuye T, Geneta T: Prevalence of domestic violence and associated factors among pregnant women attending antenatal care service at University of Gondar Referral Hospital, Northwest Ethiopia. BMC Womens Health 2018, 18(1):4-11. 
18. Makayoto L, Omolo J, Kamweya A, Harder V, Mutai J: Prevalence and associated factors of intimate partner violence among pregnant women attending Kisumu District Hospital, Kenya. Matern Child Health J 2013, 17(3):441-447.

19. Okada M, Akiko L, Hoga K, Luiza A, Borges V, Sartori De Albuquerque R: Domestic violence against pregnant women Violência doméstica na gravidez. Acta Paul Enferm 2015, 28(283):270-4270.

20. Shrestha M, Shrestha S, Shrestha B: Domestic violence among antenatal attendees in a Kathmandu hospital and its associated factors: A cross-sectional study. BMC Pregnancy Childbirth [Internet] 2016, 16(1):1-10.

21. Pires de Almeida C, Sá E, Cunha F, Pires E: Violence during pregnancy and its effects on mother-baby relationship during pregnancy. J Reprod Infant Psycho/ 2013, 31(4):370-380.

22. Ghodrati F, Setodeh S, Akbarzadeh M: A study of the effect of domestic violence on maternalneonatal attachment in prim gravida women referred to hospitals affiliated to Shiraz university of medical sciences. Biomed Res 2017, 28(8):3794-3797.

23. Ghafari M, Nahidi F, Masjedi A, Nasiri M: Correlation between physical violence and mother-fetus attachment in pregnant mothers visiting the healthcare centers of mashhad. J Urmia Nurs Midwifery Fac 2018, 16(6):37-46.

24. Cranley M: Development of a tool for the measurement of maternal attachment during pregnancy. Nurs Res 1981.

25. Khoramrody R: The effect of mothers touch on maternal fetal attachment. Tehran Iran Univ Med Sci 2000.

26. Delavari $M$, Mirghafourvand $M$, Mohammad alizadeh gharandabi $S$ : The relationship of maternalfetal attachment and depression with social support in pregnant women referring to health centers of Tabriz-Iran, 2016. J Matern Fetal Neonatal Med 2018, 31(8):2450-2456.

27. Alhusen J, Gross D, Hayat M, Woods A, Sharps P: The influence of maternal-fetal attachment and health practices on neonatal outcomes in low-income, urban women. Res Nurs Heal 2012, 35(2):112120.

28. O’Malley E, Walsh M, Reynolds C, Kennelly M, Sheehan S, Turner M: A cross-sectional study of maternal-fetal attachment and perceived stress at the first antenatal visit. J Reprod Infant Psychol [Internet] 2019, 00(00):1-10.

29. Pun K, Rishal P, Darj E, Infanti J, Shrestha S, Lukasse M: Domestic violence and perinatal outcomes A prospective cohort study from Nepal. BMC Public Health 2019, 19(1):1-9.

30. Yohannes K, Abebe L, Kisi T, Demeke W, Yimer S, Feyiso M: The prevalence and predictors of domestic violence among pregnant women in Southeast Oromia , Ethiopia. 2019:1-10.

31. Ali Kamali M, Rahimi Kian F, Mir Mohammad Ali M, Mehran A, Shafie E: Comparison of domestic violence and its related factors in pregnant women in both urban and rural population in Zarand city, 2014. J Clin Nurs Midwifery (J Clin Nurs Midwifery) 2015 2015, 4(2):69-78.

32. No Title [Internet]. 
33. Vogel J: Effective gender-based violence screening tools for use in primary health care settings in Afghanistan and Pakistan: a systematic review. East Mediterr Heal J 2013, 19(3):219-226. 